\title{
The effect of cold work on the transformation kinetics and texture of a zirconium alloy during fast thermal cycling
}

DOI:

10.1016/j.msea.2019.01.047

\section{Document Version}

Accepted author manuscript

Link to publication record in Manchester Research Explorer

\section{Citation for published version (APA):}

Nguyen, C. T., Romero, J., Ambard, A., Preuss, M., \& Quinta da Fonseca, J. (2019). The effect of cold work on the transformation kinetics and texture of a zirconium alloy during fast thermal cycling. Materials Science and Engineering A, 746, 424-433. https://doi.org/10.1016/j.msea.2019.01.047

\section{Published in:}

Materials Science and Engineering $A$

\section{Citing this paper}

Please note that where the full-text provided on Manchester Research Explorer is the Author Accepted Manuscript or Proof version this may differ from the final Published version. If citing, it is advised that you check and use the publisher's definitive version.

\section{General rights}

Copyright and moral rights for the publications made accessible in the Research Explorer are retained by the authors and/or other copyright owners and it is a condition of accessing publications that users recognise and abide by the legal requirements associated with these rights.

\section{Takedown policy}

If you believe that this document breaches copyright please refer to the University of Manchester's Takedown Procedures [http://man.ac.uk/04Y6Bo] or contact uml.scholarlycommunications@manchester.ac.uk providing relevant details, so we can investigate your claim.

\section{OPEN ACCESS}




\title{
The effect of cold work on the transformation kinetics and texture of a Zirconium alloy during fast thermal cycling
}

\section{Chi-Toan Nguyen ${ }^{1}$, Javier Romero ${ }^{2}$, Antoine Ambard ${ }^{3}$, Michael Preuss ${ }^{1}$, João \\ Quinta da Fonseca ${ }^{1}$}

\author{
${ }^{1}$ Materials Performance Centre, The University of Manchester, M13 9PL, UK \\ ${ }^{2}$ Westinghouse Electric Company, Columbia, South Carolina, USA \\ ${ }^{3}$ EDF R\&D, Centre de Renardière, Moret-sur-Loing 77818, France
}

Keywords: fast heating rate, kinetics of phase transformation, texture, variant selection, loss of coolant accidents

\begin{abstract}
The effect of cold-work on the transformation kinetics and texture evolution after fast temperature cycling were studied in a dilute zirconium alloy. It was found that coldwork delays the onset of phase transformation and helps randomise the texture after the transformation. Samples of Zircaloy-4 in two conditions, cold-rolled to $70 \%$ reduction and fully recrystallised, were heated above the $\beta$-transus at a fast rate of $100^{\circ} \mathrm{Cs}^{-1}$ using resistive heating and without constraint. Electrical resistivity was used to measure the phase fraction during heating and electron back-scatter diffraction was used to measure the texture before and after the thermal cycle. Whereas previous work on titanium suggested that cold-work leads to texture strengthening after transformation, these new experiments show that, when the heating rate is fast enough, recrystallisation is incomplete on heating, which slows down the start of transformation, leading to a random $\alpha$-texture after cooling. The texture in the recrystallised material after $\beta$ heattreatment is non-random but different from the start, a consequence of both a stronger $\beta$-texture after grain growth and stronger variant selection on cooling. This variant selection can be mostly explained by $\alpha$-nucleation at special $\beta$-grain boundaries. These results demonstrate that prior deformation has a strong effect on the textures produced after $\beta$-heat treatment when heating rates are fast. This has implications for the anisotropy of nuclear cladding components after loss-of-coolant (LOCA) and reactivity-
\end{abstract}


initiated accidents (RIA) but also more widely for the manufacturing of zirconium and titanium using welding or additive layer manufacturing where the heating rates are high.

\section{Introduction}

Alloys of zirconium and titanium undergo pronounced microstructural changes when heated above the allotropic phase transformation temperature. These changes are exploited in the processing of wrought alloys and characterise the final microstructures in processes like additive layer manufacturing (ALM) and welding. For example in $\mathrm{Zr}$ alloys used in nuclear fuel claddings, these changes can happen during loss-of-coolant (LOCA) and reactivity-initiated accidents (RIA), affecting the material behaviour during and after the incidents [1]. On heating, dilute Ti and $\mathrm{Zr}$ alloys transform from an $\alpha$ hexagonal-close-packed (hcp) to a $\beta$ body-centre-cubic (bcc) phase transformation which is completed once the $\beta$-transus temperature is exceeded, at around $960^{\circ} \mathrm{C}$ for Zircaloy-4 [2] and $913^{\circ} \mathrm{C}$ for CP-Ti grade 2 [3] at equilibrium conditions. On heating, $\beta$ nucleates and grows between and within $\alpha$ grains until the $\alpha$ phase is consumed, after which $\beta$ grains can grow unrestricted. On cooling, these grains transform back into $\alpha$, usually producing a $\beta$-quenched Widmanstätten microstructure, with characteristic dimensions determined primarily by the prior $\beta$-grain structure and cooling rates [4], producing martensite at very fast cooling rates.

These morphological changes during a $\beta$-cycle are accompanied by changes in the crystallographic texture, which in turn have a dominant effect on the strength and anisotropy of the alloys. The transformation follows the well-established Burgers relationship [5], which should produce a weak, nearly random texture following a complete $\beta$-cycle. However, in practice, experiments have shown a number of different behaviours, from strengthening of the starting texture [6-10] to weakening [11] and the formation of a non-random but different transformed texture [8,12]. The most likely explanation for these differences is differences in the material studied, like composition or microstructure, or a difference in the parameters of the thermal cycle, like heating and cooling rates. Indeed, it has been shown that the kinetics of the transformation is affected by alloy composition $[13,14]$, heating rates $[2,15-17]$ and cooling rates $[4,18]$. However, it is not clear what effect, if any, cold work would have on the kinetics and microstructure evolution during $\beta$-cycling. 
Defects introduced by deformation could help nucleate the precipitating phase and hence catalyse the phase transformation. Since the distribution of such defects will be linked to slip activity, cold-work could therefore be a strong variant selection mechanism [12]. On the other hand, because deformation distorts the lattice and introduces local stresses, cold work could hinder the growth of the second phase during transformation, slowing down the transformation. The recrystallisation temperatures of these alloys are well below their phase transformation temperatures, therefore interactions between deformation induced defects and the phase transformation are only likely when either deformed material is heated rapidly enough to avoid recrystallisation or when the material is deformed during transformation. Fast heating rates are typical of ALM and welding processes as well as LOCA and RIA accidents, whereas dynamic interactions will occur during thermomechanical processing, like hot forging or rolling, and sometimes also during welding.

In this paper, the effect of prior deformation on the phase transformation was studied in Zircaloy-4, an industrially important $\mathrm{Zr}$ alloy. The aim was to determine the effect of cold-work on the kinetics of phase transformation and on the resultant transformed microstructure, including texture, under relatively fast heating rates. Experiments were designed to replicate the typical heating and cooling rates of LOCA and RIA, where temperatures reach over $1000^{\circ} \mathrm{C}$, at rates ranging from 5 to $100^{\circ} \mathrm{Cs}^{-1}$. Resistive heating was used to heat cold-worked (CW) and recrystallised (RX) samples whilst the phase fractions during transformation were measured using electrical resistivity. The microstructure and texture were characterised using Electron-Backscatter Diffraction (EBSD) before and after thermal cycling and interpreted in terms of the mechanisms of phase transformation. The changes in texture measured were compared to those predicted by the Burgers relationship to assess the degree of variant selection occurring.

\section{Materials and experimental methods}

\subsection{Materials}

The material studied was Zircaloy-4 provided by Westinghouse Electric Co. as $0.67 \mathrm{~mm}$ thick cold-worked (CW) sheet of $70 \%$ reduction, with the chemical composition of $\mathrm{Zr}$ $1.27 \mathrm{Sn}-0.17 \mathrm{Fe}-0.10 \mathrm{Cr}-0.12 \mathrm{O}(\% \mathrm{wt})$. To produce the recrystallised (RX) material, this sheet was recrystallised at $650^{\circ} \mathrm{C}$ for 15 minutes in air using an Electrical-Thermal- 
Mechanical Tester (ETMT) by resistive heating. The samples tested in the ETMT were produced by electrical discharge machining of the sheet. They were $2.0 \mathrm{~mm}$ wide and had a gauge length of $16.0 \mathrm{~mm}$.

The starting microstructure was characterized via optical microscopy and EBSD and is shown in Fig. 1. While the grains in RX Zircaloy-4 are equiaxed, with a mean size of $5.8 \mu \mathrm{m}$, those in the CW Zircaloy-4 are elongated along the rolling direction (RD), as shown in Fig. 1a-c. The texture of the recrystallised state shows a split of the basal poles from the normal direction (ND) towards the transverse direction (TD) and a 'rotation' of $11 \overline{2} 0$ poles to RD, Fig. $1 \mathrm{~d}$. The texture of the as-rolled material is characterized by a strong alignment of the basal poles or $<\mathrm{c}>$ axis to ND and a spread of the $11 \overline{2} 0$ in the rolling plane with stronger alignments at about $\pm 30^{\circ}$ from RD to TD, Fig. 1e. These texture observations are consistent with previous measurements on rolled zirconium alloys $[11,19]$.
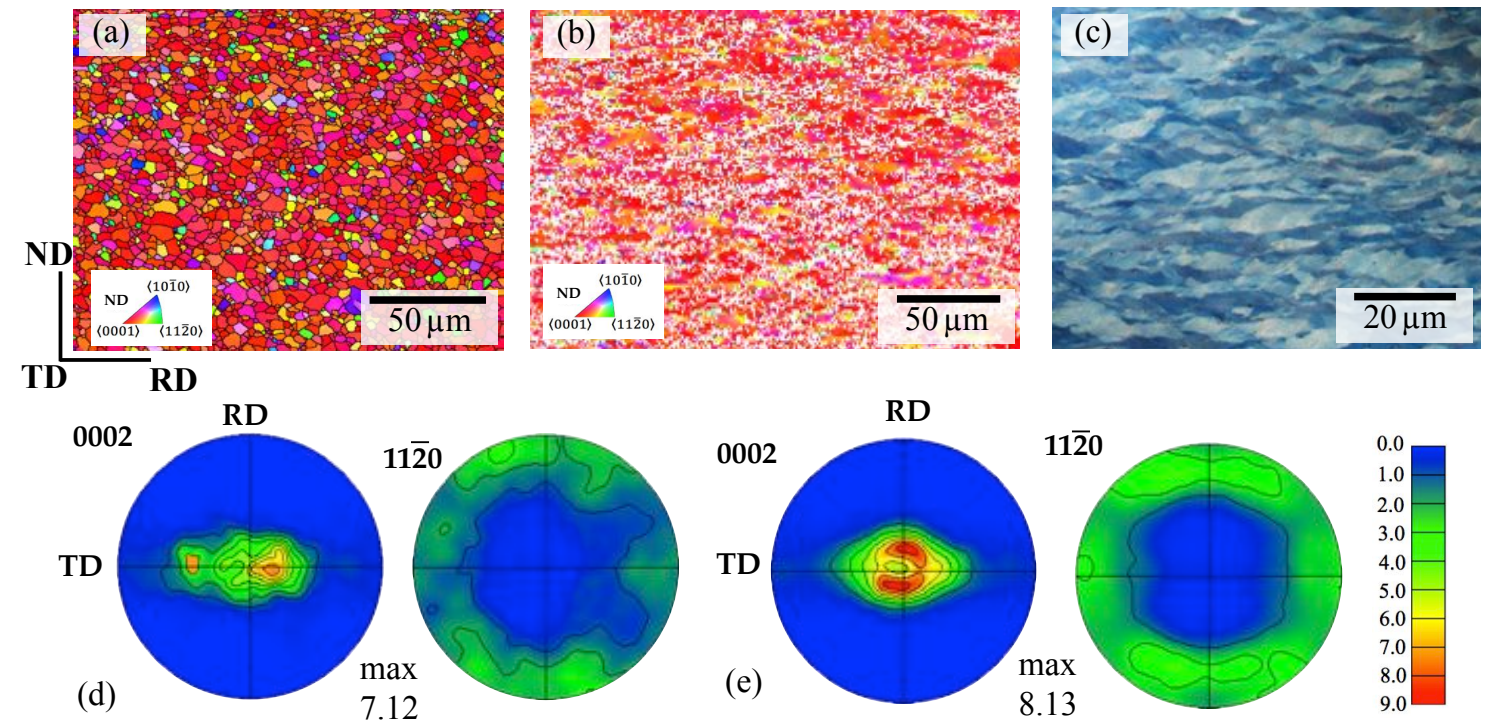

Fig. 1: EBSD inverse pole figure (IPF) colour maps in ND and pole figures (PF) of RX (a and d respectively) and CW (b and e respectively) Zircaloy-4 before heating; optical micrograph (c) of the CW revealing elongated grains in RD.

\subsection{Fast thermal cycling}

The samples were heated and cooled in air by resistive heating using direct current on an ETMT. Sample temperature was controlled via an R-type (Pt/Pt-13\%Rh) $0.15 \mathrm{~mm}$ 
diameter thermocouple spot-welded at the mid-length of the heated samples. Samples were heated at the rate of $100^{\circ} \mathrm{Cs}^{-1}$ to $1100^{\circ} \mathrm{C}$ and then held for 3 seconds before cooling at $50^{\circ} \mathrm{Cs}^{-1}$ to room temperature. In an attempt to compare the microstructure and texture of the two materials just before phase transformation, both materials were heated at $100^{\circ} \mathrm{Cs}^{-1}$ up to $900^{\circ} \mathrm{C}$ for 2 seconds on the ETMT (shortest possible holding time) and then fast cooled at $100^{\circ} \mathrm{Cs}^{-1}$ to room temperature. To study the effect of $\beta$ grain growth on the high temperature $\beta$-texture and then on the final transformed $\alpha$-texture after cooling, some $\mathrm{CW}$ samples were held for the longer time of 10 seconds at $1100^{\circ} \mathrm{C}$, after having been heated using the same $100^{\circ} \mathrm{Cs}^{-1}$ heating rate.

During the thermal cycles the load was controlled at $0.0 \mathrm{~N}$ to allow the heated samples to expand freely. The load trace recorded during the tests confirmed that no stress was applied on the samples at any point in the cycle. All the thermal cycles were carried out in air and so the oxygen uptake during heating may slightly affect the phase fractions measured [17]. However, because of the fast heating rates of $100^{\circ} \mathrm{Cs}^{-1}$ used, this effect on the measured $\beta$-fractions is expected to be very small (less than $3 \%$ ) [17].

\subsection{Determination of $\beta$ approach curves by the electrical resistivity method}

The electrical resistivity method has been used widely to study the kinetics of phase transformation [13,17,20-23]. It consists of measuring the resistivity of the sample during heating and interpreting the result in terms of phase fraction changes. The start and finish transformation temperatures are assumed to occur when the first time derivative of resistivity is equal to zero. The phase fractions are then determined using a rule of mixtures after fitting the electrical resistivity of each phase [24]. Previous work has shown that the $\beta$-fractions determined by electrical resistivity methods agree well with those measured by in-situ high energy synchrotron X-ray diffraction [17]. Measurements were repeated for each condition.

\subsection{Texture measurements and predictions without variant selection}

EBSD was used to characterise the microstructure and texture of the $\alpha$-phase before phase transformation and after the complete fast $\beta$ thermal cycles. EBSD maps were obtained from the centre of the heated samples on both the normal surface (the TD and RD plane) with an area of $1000 \mu \mathrm{m} \times 750 \mu \mathrm{m}$ and the cross-section surface (the ND and 
RD plane) with an area of $1000 \mu \mathrm{m} \times 380 \mu \mathrm{m}$. The orientations from both maps were used to calculate the bulk texture. These areas cover 188 prior $\beta$-grains in the RX samples and 400 prior- $\beta$ grains in the $\mathrm{CW}$ samples. EBSD measurements were made on a FEI Sirion field emission gun scanning electron microscope equipped with the Aztec software for data acquisition. The measurement step size was $0.5 \mu \mathrm{m}$ for all the EBSD maps. The hkl Channel 5 software was used for texture analysis by using the harmonic method [25] with a $10^{\circ}$ spread. The software was also used to visualize low-angle $\left(<10^{\circ}\right.$ and $>2^{\circ}$ ) due to the EBSD angular limitation [26]) and high-angle $\left(\geq 10^{\circ}\right)$ grain boundaries to estimate the extent of recrystallisation of materials before phase transformation.

The high temperature $\beta$-grains were reconstructed from the final $\alpha$-texture by using a $\beta$ reconstruction procedure based on analysis of $\alpha$-variant misorientation with its neighbours [27]. A $2^{\circ}$ minimum $\alpha$-variant misorientation was used to achieve a common reconstructed $\beta$-grain with the tolerance of $3^{\circ}$. The reconstructed high-temperature $\beta$ texture represents the experimental high-temperature $\beta$ texture before cooling thanks to the unique solution of reconstructed $\beta$ texture by the $\alpha$ variant-based technique [27-30]. The degree of variant selection upon cooling was estimated by comparing the orientation distribution function (ODF) of the experimental $\alpha$-texture after the fast $\beta$ thermal cycles and the predicted $\alpha$-texture without variant selection, assuming all $12 \alpha$ variants activate with the same probability on cooling from $\beta \rightarrow \alpha$. The predicted transformed $\alpha$-texture without variant selection was computed from the high temperature reconstructed $\beta$-texture by changing the crystal symmetry of the parent $\beta$ bcc phase to that of the transformed $\alpha$-hcp phase and then transferring the parent orientations into the new crystal symmetry by applying the Burgers orientation relationship which can expressed as the transformation matrix corresponding to the Euler angles of $\left(135^{\circ}, 90^{\circ}, 354.74^{\circ}\right)[29,31]$. Similarly, the predicted $\beta$-texture on heating without variant selection was determined from the $\alpha$-texture by changing the crystal symmetry and then applying the inverse transformation matrix. The prediction and ODF plots were obtained by using the software package TEXTAN-III [32]. 


\section{Results}

\section{1. $\beta$ approach curves}

The $\beta$-approach curves for 2 samples in each material condition are reported in Fig. 2. The error bars of $\beta$ fractions were calculated by using the upper and lower bounds given by the rule of mixtures, which represent the effect of two-phase distribution and microstructure of the actual material $[17,24]$. Despite of the slight sampling variability, there is a clear difference in the $\beta$-approach curves of the $\mathrm{CW}$ and $\mathrm{RX}$ material, as can be seen in Fig. 2a. The starting phase transformation temperature is at $883^{\circ} \mathrm{C}$ and $888^{\circ} \mathrm{C}$ for the $2 \mathrm{RX}$ samples and at $895^{\circ} \mathrm{C}$ and $918^{\circ} \mathrm{C}$ for the $\mathrm{CW}$ states. The ending transformation temperature of the RX samples varies from 990 to $1015^{\circ} \mathrm{C}$ and that of the $\mathrm{CW}$ samples are from 1005 to $1020^{\circ} \mathrm{C}$. More importantly, when the phase transformation occurs, the $\mathrm{CW}$ material takes almost two times longer to increase to $10 \%$ of the $\beta$ fraction than the $\mathrm{RX}$ material. This means that the $\beta$ volume fraction is higher in the RX material at any temperature up until $980^{\circ} \mathrm{C}$ (about $90 \% \beta$ fraction). These results imply that the cold-work in the starting microstructure acts to delay the phase transformation, particularly at the start.

The $\beta$-approach curves of the RX and CW Zircaloy-4 at the constant heating rate of $100^{\circ} \mathrm{Cs}^{-1}$, Fig. $2 \mathrm{a}$, are similar to ' $\mathrm{S}$ ' shaped transformation-time curves in isothermal phase transformation. Thus, to study the kinetics of phase transformation in $\mathrm{RX}$ and $\mathrm{CW}$ Zircaloy-4 in non-isothermal conditions, a modified Kolmogorov-Johnson-MehlAvrami (KJMA) relationship [2,15,33] was used that is given below

$$
\% \beta=1-\exp \left(-\mathrm{K}\left(\mathrm{T}-\mathrm{T}_{0}\right)^{\mathrm{n}}\right)
$$

where $\% \beta$ is the fraction of $\beta$-phase at temperature $T, T_{0}$ is the starting transformation temperature (the mean starting transformation temperature of the two samples was used for the KJMA analysis), $K$ is related to the activation energy of the phase transformation for both nucleation and growth, and $n$ is the KJMA exponent [34]. The KJMA exponent, $n$, was determined by the slope of the plots $\ln (-\ln (1-\% \beta))$ against $\ln \left(T-T_{0}\right)$, Fig. 2b.The KJMA exponent, $n$, for the RX material was found to be constant and equal to 1.95 during the entire phase transformation while that of the $\mathrm{CW}$ material changes, as shown in the plots of $\ln (-\ln (1-\% \beta))$ against $\ln \left(T-T_{0}\right)$ in Fig. $2 \mathrm{~b}$. The $n$ exponent of CW 
material is smaller at 1.5 up to $12 \% \beta$ volume fraction, and increases significantly to 2.8 until $50 \% \beta$ before reducing to around 2 at higher $\% \beta$. The difference in KJMA exponents suggests that the two materials have different rates of nucleation and growth, and the relative contribution of nucleation and growth changes in the $\mathrm{CW}$ material during heating.
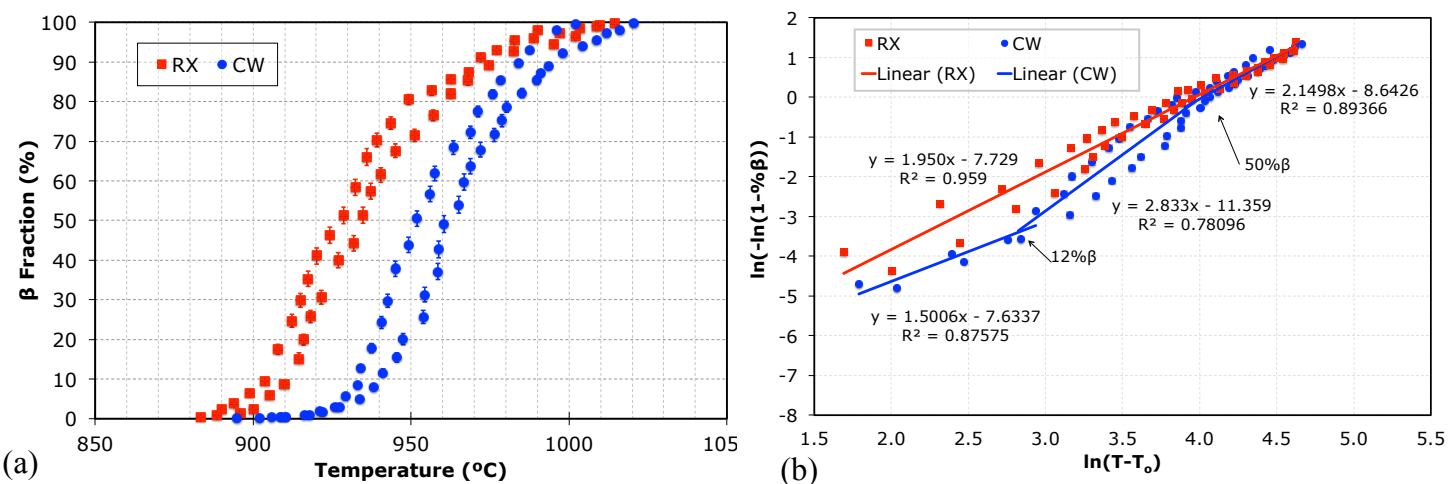

Fig. 2: $\beta$-approach curves of RX and CW Zircaloy-4 at $100^{\circ} \mathrm{Cs}^{-1}$ measured by electrical resistivity method.

\subsection{Microstructure and texture evolution during the fast heating cycles}

\subsubsection{Microstructure and texture of the $\alpha$-phase before phase transformation}

After fast heating at $100^{\circ} \mathrm{Cs}^{-1}$ to just below the transformation temperature, the microstructure and texture prior to phase transformation are different between the $\mathrm{CW}$ and RX conditions, as shown in Fig. 3. Rapid heating to $900^{\circ} \mathrm{C}$ transforms the deformed elongated grains of the $\mathrm{CW}$ microstructure into small, nearly equiaxed grains, with a mean grain size of $3.74 \mu \mathrm{m}$, smaller than that of those in recrystallised material $(6.67$ $\mu \mathrm{m})$. The $\alpha$-phase pole figures of the RX and CW materials are similar to those of the starting material but with lower intensity. The RX material still shows a split of 0002 poles around ND towards TD and a significant spread of $11 \overline{2} 0$ in the rolling plane (Fig. 3c) and the CW material, retains a strong basal pole in ND (Fig. 3d), without the split of $c$-axis from ND to TD, which is characteristic of grain growth in the later stages of the recrystallisation process [11].

The correlated misorientation angles distribution and grain boundary maps of the materials after heating to $900^{\circ} \mathrm{C}$ are shown in Fig. 4. The RX material exhibits the 
highest frequency at around $30^{\circ}$ misorientation angle and a spread of misorientation angles from low (less than $10^{\circ}$ ) to high (up to $90^{\circ}$ ), Fig. $4 \mathrm{a}$, while before heating the $\mathrm{CW}$ material shows a high frequency of low misorientation angles (less than $10^{\circ}$ ) that is characteristic of a deformed microstructure. After the 2-second $900^{\circ} \mathrm{C}$ anneal, this high frequency of low misorientation angles decreases but still remains the highest for the sample, as shown in Fig. 4b.

The corresponding grain boundary maps before phase transformation are shown in Fig. $4 \mathrm{c}$ and $4 \mathrm{~d}$ for the RX and CW Zircaloy-4 respectively. They confirm that, unlike the RX material, the $\mathrm{CW}$ material contains a large number of unrecrystallised grains whose the grain boundary misorientation is less than $10^{\circ}$ and higher than $2^{\circ}$. The unrecrystallised grains appear in clusters and are equally distributed in the microstructure. At this high heating rate, the $\mathrm{CW}$ material is only partially recrystallised at $900^{\circ} \mathrm{C}$ and therefore, that the microstructures of the two starting conditions are still different at this stage. This recrystallisation delay is likely to be even stronger during the actual $\beta$-cycle since there is no 2-second hold before the transformation.

(a)

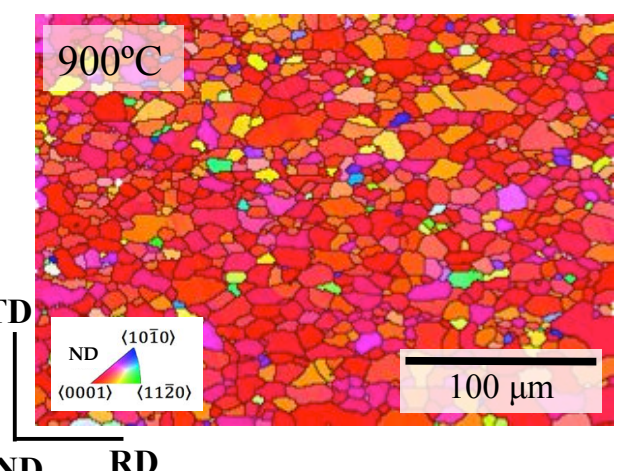

(c)
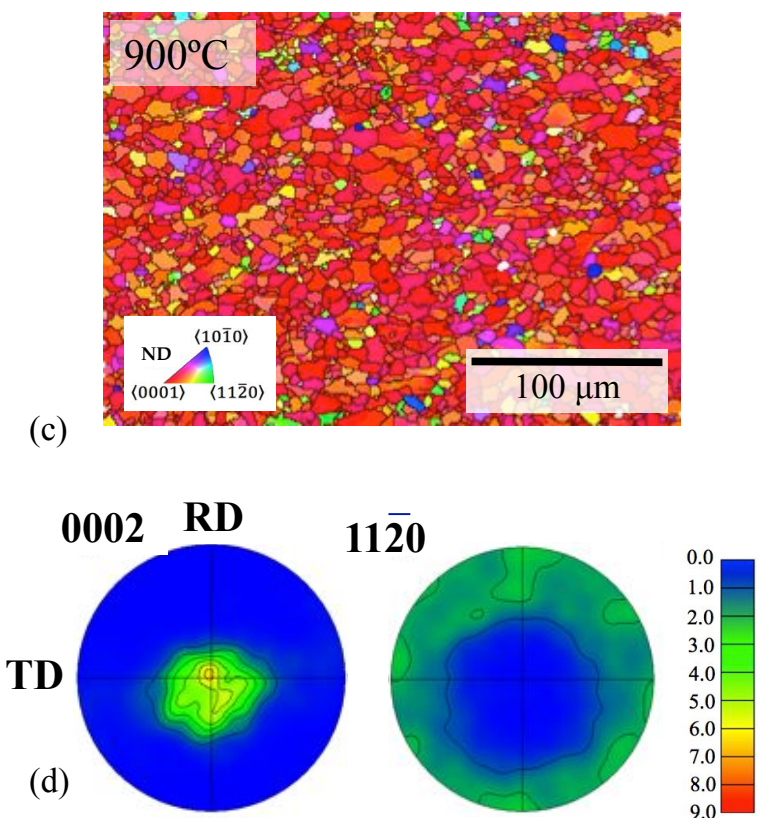

(d)

(b)

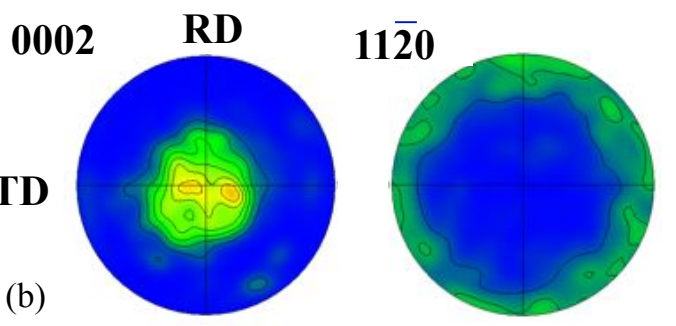

Fig. 3: EBSD IPF colour maps in ND and PF of RX (a and b respectively) and CW (c and d respectively) Zircaloy- 4 at $900^{\circ} \mathrm{C}$ after heating $100^{\circ} \mathrm{Cs}^{-1}$ and holding for 2 seconds before rapidly cooling to room temperature. 


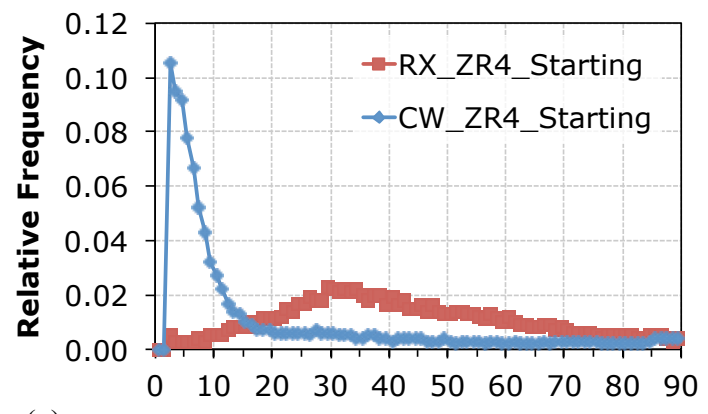

(a)

Misorientation angle $\left({ }^{\circ}\right)$

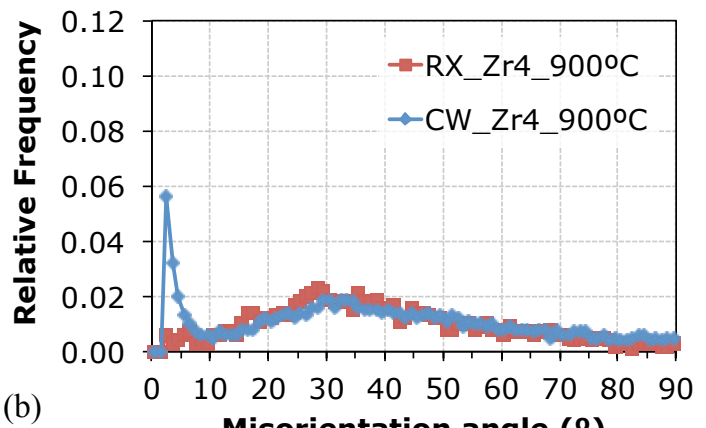

(b)

Misorientation angle $\left({ }^{\circ}\right)$

(c)

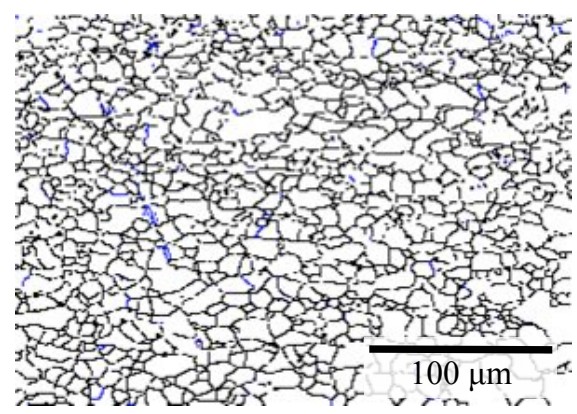

(d)

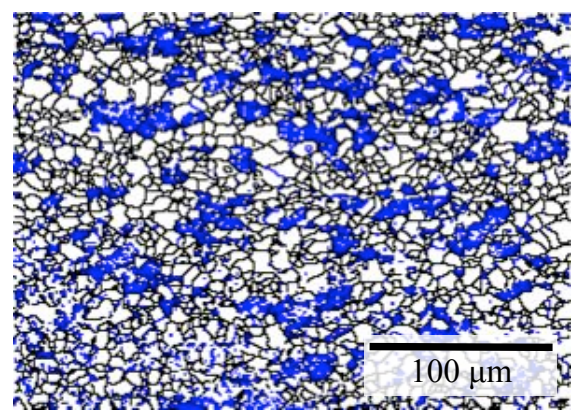

Fig. 4: EBSD misorientation angle distribution (discard the misorientation less than $2^{\circ}$ due to EBSD limitation) of RX and CW Zircaloy-4 at room temperature (a) and

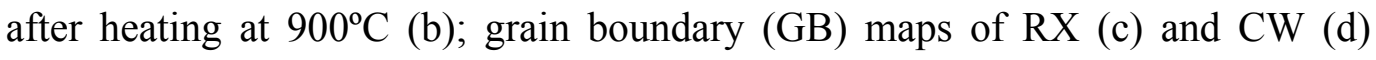
Zircaloy-4 after heating at $900^{\circ} \mathrm{C}$ (black GBs indicate higher $10^{\circ}$ of misorientation and blue less than $10^{\circ}$ ).

\subsubsection{Microstructure and texture of the $\alpha$-phase after the complete heating cycles}

After the complete $\beta$-cycles, both materials have a Widmanstätten microstructure as shown in the inverse pole figure (IPF) colour map in Fig. 5. This confirms that the phase transformation $\alpha \rightarrow \beta$ is complete in all the fast thermal cycles. The mean grain size of the $\alpha$-lamellae in the $\mathrm{CW}$ sample is identical to that in the recrystallised sample, as shown in Table 1 . However, the reconstructed $\beta$ grain size in the $\mathrm{CW}$ material is significantly smaller $(46 \mu \mathrm{m})$ than that in the RX material $(70 \mu \mathrm{m})$.
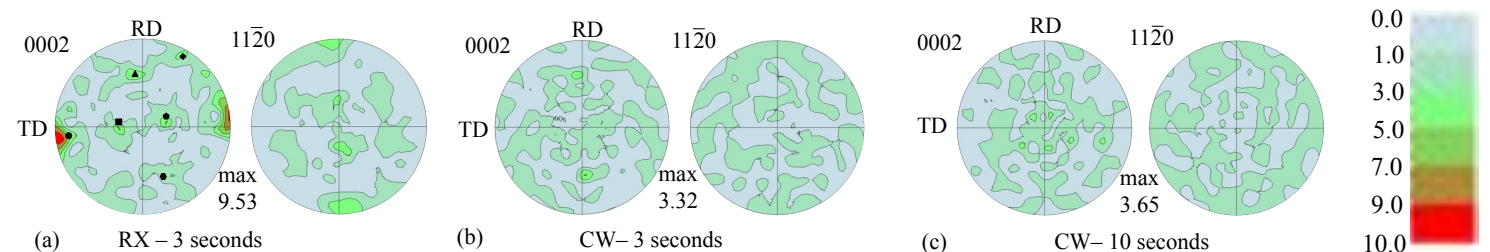

Fig. 5: PF of the $\alpha$-phase after heating at $100^{\circ} \mathrm{Cs}^{-1}$ to $1100^{\circ} \mathrm{C}$ and cooling at $50^{\circ} \mathrm{Cs}^{-1}$ of RX (a), CW holding for 3 seconds (b) and for 10 seconds (c) Zircaloy-4. 
Table 1: Mean grain size of inherited $\alpha$-lamellae and $\beta$-reconstructed in both $\mathrm{CW}$ and RX Zircaloy-4, obtained by the linear intercept method implemented in the hkl Channel 5 software with $10^{\circ}$ of critical misorientation for EBSD measurements.

\begin{tabular}{|c|c|c|c|c|}
\hline \multirow{2}{*}{$\begin{array}{l}\text { Zircaloy- } 4 \text { after } \\
\text { the fast } \beta \text {-cycle }\end{array}$} & \multicolumn{2}{|c|}{$\begin{array}{c}\text { TD measurement } \\
\text { Mean grain size }(\mu \mathrm{m})\end{array}$} & \multicolumn{2}{|c|}{$\begin{array}{c}\text { ND measurement } \\
\text { Mean grain size }(\mu \mathrm{m})\end{array}$} \\
\hline & $\begin{array}{c}\text { Inherited } \alpha- \\
\text { lamellae }\end{array}$ & $\begin{array}{c}\text { Reconstructed } \beta \text { - } \\
\text { grains }\end{array}$ & $\begin{array}{c}\text { Inherited } \alpha- \\
\text { lamellae }\end{array}$ & $\begin{array}{c}\text { Reconstructed } \beta- \\
\text { grains }\end{array}$ \\
\hline CW - 3 seconds & 4.45 & 45.38 & 8.25 & 45.88 \\
\hline $\mathrm{RX}-3$ seconds & 4.77 & 73.94 & 8.35 & 69.79 \\
\hline $\mathrm{CW}-10$ seconds & \multicolumn{2}{|c|}{ Not measured } & 10.39 & 65.77 \\
\hline
\end{tabular}

The $\alpha$-phase texture after transformation is completely different from the starting texture in both materials. The basal pole figure of the transformed RX condition shows 6 separate maxima, with the 0002 poles along TD significantly stronger than the others, Fig. 6a. The texture index [35] of the final $\alpha$-texture in RX samples is 2.33 while that of the starting $\alpha$-texture is 3.52 . This indicates that the transformed $\alpha$-texture is weakened by the $\beta$-cycle. Although the transformed $\alpha$-texture has one particular 0002 component aligned in TD with higher pole intensity than that of the other components of the starting $\alpha$-texture, the transformed $\alpha$-texture contains several other weak components, leading to a weaker $\alpha$-texture in the RX sample than the initial texture. In contrast, as Fig. $6 \mathrm{~b}$ shows, the texture of $\mathrm{CW}$ material is almost random with a texture index of 1.31 and hence much weaker than both the starting $\mathrm{CW}$ texture and the transformed $\mathrm{RX}$ material.

Increasing the $\beta$-holding time to $10 \mathrm{~s}$ in the $\mathrm{CW}$ material does not produce a strong transformed $\alpha$-texture although the mean $\beta$ grain size increases to be similar to that in the RX material, Fig. 5e and Table 1. Although the texture sharpens slightly, with an index of 1.66, it remains essentially random, Fig. 6c. Promoting $\beta$-grain growth in the $\mathrm{CW}$ material only strengthens the transformed $\alpha$-texture almost imperceptibly. 

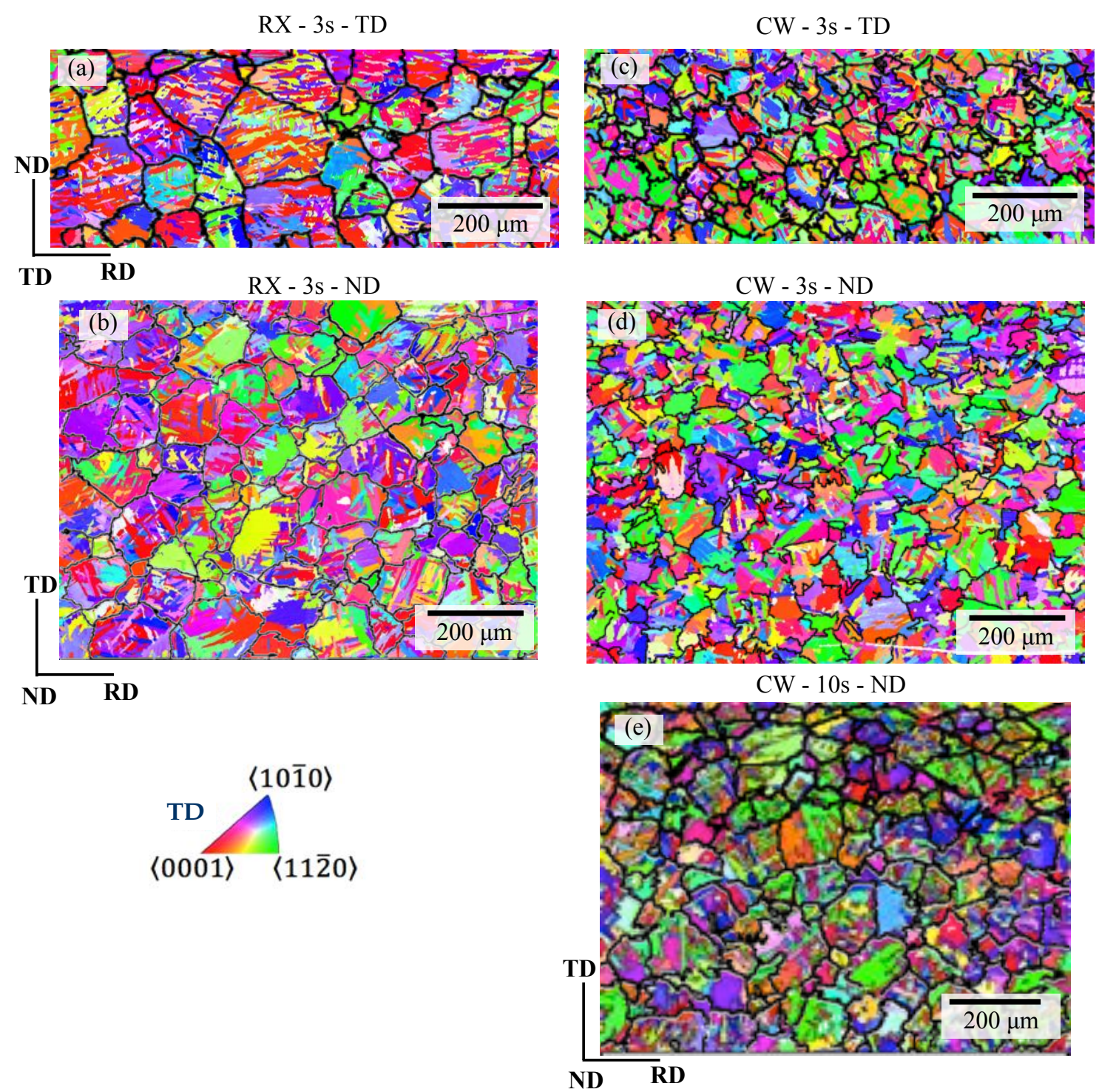

Fig. 6: IPF colour maps in TD of the $\alpha$-phase in cross-section plane and normal plane after heating at $100^{\circ} \mathrm{Cs}^{-1}$ to $1100^{\circ} \mathrm{C}$ and cooling at $50^{\circ} \mathrm{Cs}^{-1}$ of $\mathrm{RX}$ (a and b), CW holding for 3 seconds (c and d) and CW holding for 10 seconds Zircaloy-4 (e); Black lines are reconstructed $\beta$-grain boundaries by the $\alpha$-variant model [27].

\section{Discussion}

\subsection{The effect of microstructure on the kinetics of phase transformation}

The results of the fast heating experiments showed that the presence of cold work delays the start of the transformation and slows it down in the initial stages. The allotropic phase transformation in these alloys is a discontinuous process, occurring via nucleation and growth [36]. High angle $\alpha$-grain boundaries will act as preferential sites 
for $\beta$-grain nucleation in both $\mathrm{RX}$ and $\mathrm{CW}$ materials. The $\mathrm{CW}$ material has a higher high grain-boundary content and also contains large numbers of low-angle grain boundaries, which probably also act as preferred nucleation sites. Therefore the number of nucleation sites should be higher in the $\mathrm{CW}$ material than in the recrystallised material. Despite this, the rate of transformation is clearly lower in the $\mathrm{CW}$ material.

KJMA exponents cannot be interpreted unambiguously in terms of microstructural changes, especially since the temperature is constantly increasing. Nevertheless, the very low value of the exponent in the modified KJMA exponent below 2 at the start of the transformation for the $\mathrm{CW}$ material suggests that the morphology of the precipitating $\beta$-phase is different from that in the RX material, where the exponent is constant at 2. One possible interpretation is that although the $\mathrm{CW}$ material contains more nucleation sites, growth of the new phase is much more difficult than in the RX case. This could be due to the much larger misorientations in the deformed $\alpha$-phase which will make growth according to the Burgers relationship more difficult. Whereas in the RX material, variants nucleating at grain boundaries can grow unimpeded across the recrystallised grains, and are large enough that their growth can be auto-catalytic, in the $\mathrm{CW}$ material there are many more small nuclei, the growth of which is limited by

the deformed structure and the presence of other stunted nuclei. Only at higher temperatures where recrystallisation can occur and produce the larger $\alpha$-grains that enable the growth at the same rate as that in the RX material. Since the $\beta$ nuclei are more diverse in the $\mathrm{CW}$ material, the transformed texture should be weaker and the misorientation between $\beta$ grains should be more diverse.

\subsection{Reconstructed high-temperature $\beta$ microstructure and texture}

The differences in the transformation textures of the two materials are probably related to the differences in recrystallisation kinetics. However, it is not possible to infer from the final $\alpha$-textures alone whether they are primarily determined by differences in variant selection or just differences in the starting texture, and whether the differences seen are established on heating, cooling or both.

To investigate the origin of the texture differences, the high-temperature $\beta$ microstructure was reconstructed from the transformed $\alpha$. The resultant $\beta$ grain boundary maps are superimposed on the $\alpha$-phase IPF maps in Fig. 5. They show that the 
prior- $\beta$ grain boundaries of the RX material are straighter than those in the $\mathrm{CW}$ samples. These differences in grain morphology are consistent with the differences in the nucleation and growth proposed to explain the different transformation kinetics. The $\mathrm{CW}$ material has a larger number of nucleation sites provided by the deformation substructure, which lead to a smaller $\beta$ grain size and the jagged appearance of the grain boundaries. In the RX material, the $\beta$ grains nucleate only at the $\alpha$ grain boundary and can grow more rapidly and interact less often with the other $\beta$-grains, leading to larger grains and straighter $\beta$ grain boundaries.

The high-temperature $\beta$-texture of the RX material is much stronger than that of the $\mathrm{CW}$ material for both 3 and 10 second holding time, Fig. 7a-c. While the high temperature $\beta$ texture of the RX samples shows the 6 maxima as labelled in Fig. 7a, those of the CW do not have a particular strong component. This could be related to the larger $\beta$ grain size in the RX samples. It has been shown before that $\beta$-grain growth can lead to texture strengthening [10] However, when the CW material was held for 10 seconds at the maximum temperature to promote grain growth, the texture strengthened very slightly, as shown in Fig. $7 \mathrm{~b}$ and $7 \mathrm{c}$. It is noticeable that after $\beta$ grain growth, the $\beta$ grain boundaries of the $\mathrm{CW}$ are straighter than those with a short holding time, although it is not clear if this difference is significant.

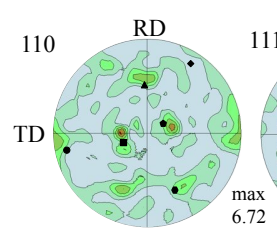

(a) $\mathrm{RX}-3$ seconds

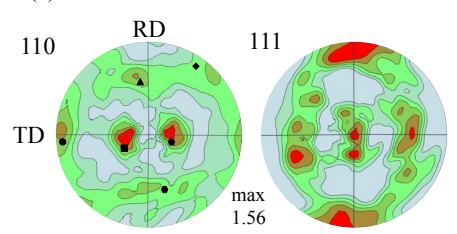

(d)

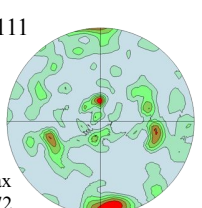

$\mathrm{RX}$

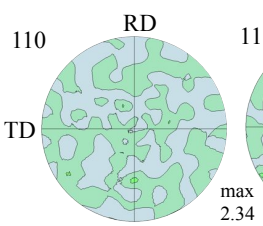

(b)

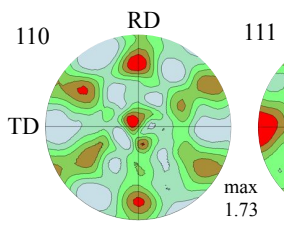

$\mathrm{CW}-3$ seconds

(e)
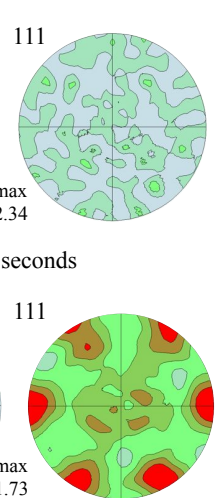

$\mathrm{CW}$

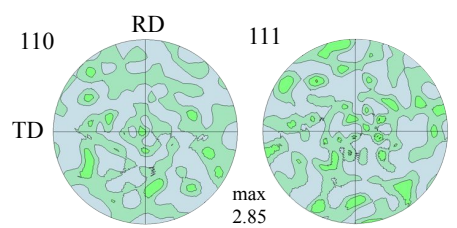

(c)

CW- 10 seconds

Fig. 7: Pole figures of the high-temperature reconstructed $\beta$-phase from the final $\alpha$ texture after cooling of RX (a), CW with a 3-second (b) and 10 second (c) hold Zircaloy-4. Pole figures of the predicted $\beta$-phase without variant selection from the $\alpha$-texture at $900^{\circ} \mathrm{C}$ before phase transformation of RX (d) and CW (e). 


\subsection{Variant selection on heating}

To further understand the formation of the high temperature $\beta$-phase texture during phase transformation and whether the variant selection during heating $\alpha \rightarrow \beta$ and/or $\beta$ grain growth occurs, the high-temperature $\beta$ textures without variant selection were predicted from the $\alpha$-texture right before phase transformation for both material conditions. The predicted $\beta$-textures calculated from the $\alpha$-texture at $900^{\circ} \mathrm{C}$, shown in Fig. 7d-e, are weaker than the corresponding reconstructed high-temperature $\beta$ texture, particularly for the RX starting condition. Also, the predicted $\beta$-texture of RX samples is weaker than that of $\mathrm{CW}$ samples. All observations above indicate that variant selection occurs during heating $\alpha \rightarrow \beta$ and/or $\beta$ grain growth in both $\mathrm{RX}$ and $\mathrm{CW}$ samples. Further, the level of variant selection is much stronger in the RX than the CW.

The fact that the high-temperature $\beta$-textures are stronger than predicted, could be due to: (1) the preferential $\beta$-grain growth of certain variants during holding in the $\beta$ temperature regime and (2) the effect of the microstructure and texture of $\alpha$-phase on the nucleation at the start of the phase transformation.

The results of the experiment with the longer $\beta$ hold to promote grain growth seem to suggest that both nucleation and growth seem to be important, since they show that the growth of grains nucleated in $\mathrm{CW}$ microstructure does not appreciably strengthen the texture, Fig. 7a-c.

In the RX Zircaloy-4, studying systematically the $\beta$-grain growth for less than 3 seconds is challenging by post-mortem ex-situ EBSD texture analysis due to the uncertainty in controlling accurate temperature and holding time less than 3 seconds in the thermal cycles. Using in-situ high-energy synchrotron X-ray diffraction (SXRD), Romero et al. [9] showed that the in-situ high-temperature $\beta$-texture right after phase transformation of CW Zircaloy-2, which is fully recrystallised during slow heating, exhibits a weak 110 component in TD while the high-temperature reconstructed $\beta$-texture after $\beta$-grain growth reveals a much stronger 110 component in TD. This implies that the strong 110 component in TD forms during $\beta$-grain growth of Zircaloy-2. However, the SXRD texture measurement by Romero et al. [9] was performed on a single sample angle where the incident beam comes only from TD of the heated samples. As a result, the 110 component in TD of the high-temperature $\beta$-texture appears to be less intense than 
the actual ones. Thus, better measurements of the $\beta$-texture right after phase transformation and during $\beta$ grain growth are required to determine at which stage the strong 110 component in TD forms in the $\beta$-phase of the RX material.

Since grain growth alone cannot explain the differences in $\beta$-texture, it would appear that the difference in starting microstructure and its effects on nucleation are crucial. The $\alpha$-textures from the moment just before phase transformation is similar in both conditions and should produce weak $\beta$-textures. However, the experimental reconstructed high-temperature $\beta$ texture is much stronger in the RX material than that in the CW material. This suggests that the presence of low-angle grain-boundaries, due to incomplete recrystallisation, hinders the development of a strong $\beta$ texture. In the $\mathrm{CW}$ material, the partially recrystallised regions provide a higher number of $\beta$-nucleation sites. Since the $\alpha$-phase microstructure has fewer straight deformation-free grain boundaries, the new $\beta$-grains probably have a wider range of orientations than those the RX material. Furthermore, the misorientation within the deformed $\mathrm{CW}$ grains could prevent the growth of $\beta$-grains. This is consistent with the observed lower $\beta$-fractions in the $\mathrm{CW}$ material than that in the RX at any temperature. The limited growth of the $\beta$ phase prevents the dominance of early $\beta$-variants during the phase transformation, making it possible for other variants that transform later to still contribute to the final texture, resulting in a weaker high-temperature $\beta$-texture. In contrast, in the $\mathrm{RX}$ condition, $\beta$ grains, nucleating on the straight recrystallised grain boundaries, can grow unconstrained into the recrystallised $\alpha$. As a consequence, slower growing $\beta$-variants cannot grow, giving rise to variant selection. This difference could be small at the end of the transformation but any size advantage at this stage will promote grain growth in the $\beta$-phase region, enhancing the effects of variant selection and producing a strong $\beta$ texture.

\subsection{Variant selection on cooling}

Although all the predicted texture components appear on cooling, the intensity of some of the components in the RX material is significantly stronger than that those predicted, as shown in Fig. 8. The $\mathrm{CW}$ material, on the other hand, also shows a difference between predicted and measured textures, but this is much smaller than in the RX case. 
Therefore, there is evidence of further variant selection on cooling, particularly for the RX material.
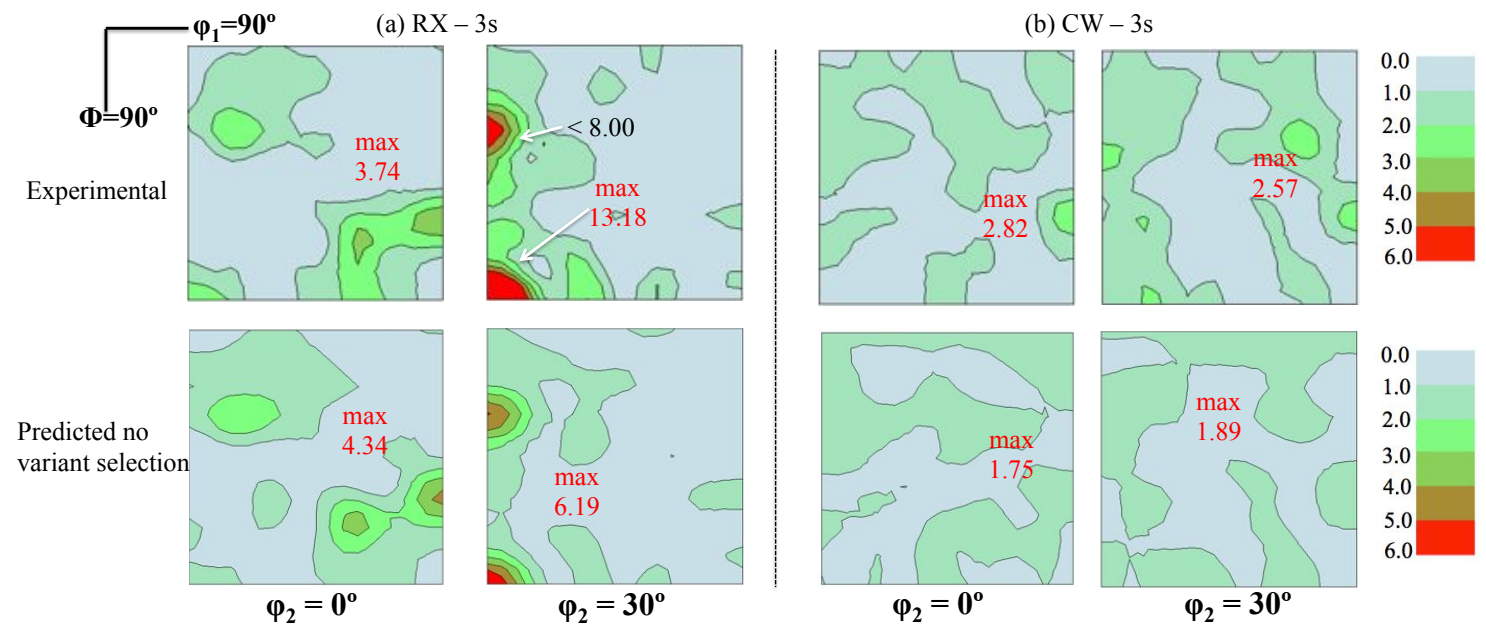

Fig. 8: Experimental ODFs of the $\alpha$-phase and the predicted $\alpha$ without variant selection of RX (a) and CW (b) Zircaloy-4 after the fast $\beta$-cycle.

Variant selection on cooling has been associated with (1) the untransformed $\alpha$-phase in incomplete phase transformation that grows back to the initial $\alpha$-texture upon cooling, providing a mechanism for texture memory [11,37]; (2) transformation-induced stress or elastic strain energy due to the change in phase volume during phase transformation $[8,38]$; (3) the presence of special $\beta$ grain boundaries, for example shared $110 \beta$ poles, formed at high temperature which promotes nucleation of certain $\alpha$-orientations followed the Burgers orientation relationship to minimize the interfacial energy between these phases $[10,39,40]$; certain $\alpha$-orientations which are nucleated first grow preferentially to become a dominant $\alpha$-variant and then a strong final $\alpha$-texture upon cooling.

In our study, the holding temperature of $1100^{\circ} \mathrm{C}$ is well above the $\beta$-transus temperature, leading to complete phase transformation in both conditions. Thus, there was no possibility of texture memory through the first mechanism. Thermal stresses and/or transformation-induced stresses also fail to explain the differences in variant selection since their magnitude is expected to be the same for both material conditions on cooling from the same temperature. There is however strong evidence of variant selection through preferred nucleation and growth on $\beta$ grain boundaries with shared 110 poles, 
especially in the RX material. Grains belonging to the orientation subset $\left(0^{\circ}, 90^{\circ}, 30^{\circ}\right)$, corresponding to the maximum in the transverse direction of the final $\alpha$-texture, are shown in Fig. 9 together with the reconstructed $\beta$-grain boundaries. This reveals that many of the $\alpha$-grains in the transverse direction (the 'red' $0002 \alpha$-grains in TD) nucleated and grew across the 'special' $\beta$-grain boundaries with a similar orientation (the 'green' $110 \beta$-grain in TD). These common $\alpha$-variants grown on both sides of their $\beta$-grain boundaries are characterized by the alignment of the 0002 poles with the same 110 directions of their parent $\beta$ grains. This alignment, which has also been reported by others [10,39-41], causes the $\left(0^{\circ}, 90^{\circ}, 30^{\circ}\right)$ variant to be selected upon cooling. In fact, the d-spacing of 110 and 0002 planes is very close and hence the $\alpha$-phase is required less energy to nucleate at the 110 grain boundaries [39]. The nucleation advantage can result in an early growth of $\alpha$-variants and hence variant selection and eventually the dominant $\alpha$-texture upon cooling. Unlike the $\mathrm{RX}$ material, the $\mathrm{CW}$ material shows almost no grains sharing 'special' $\beta$-grain boundaries (Fig. 5c-d), which is primarily a consequence of the different $\beta$-textures. This explains less variant selection observed in the CW material on cooling.

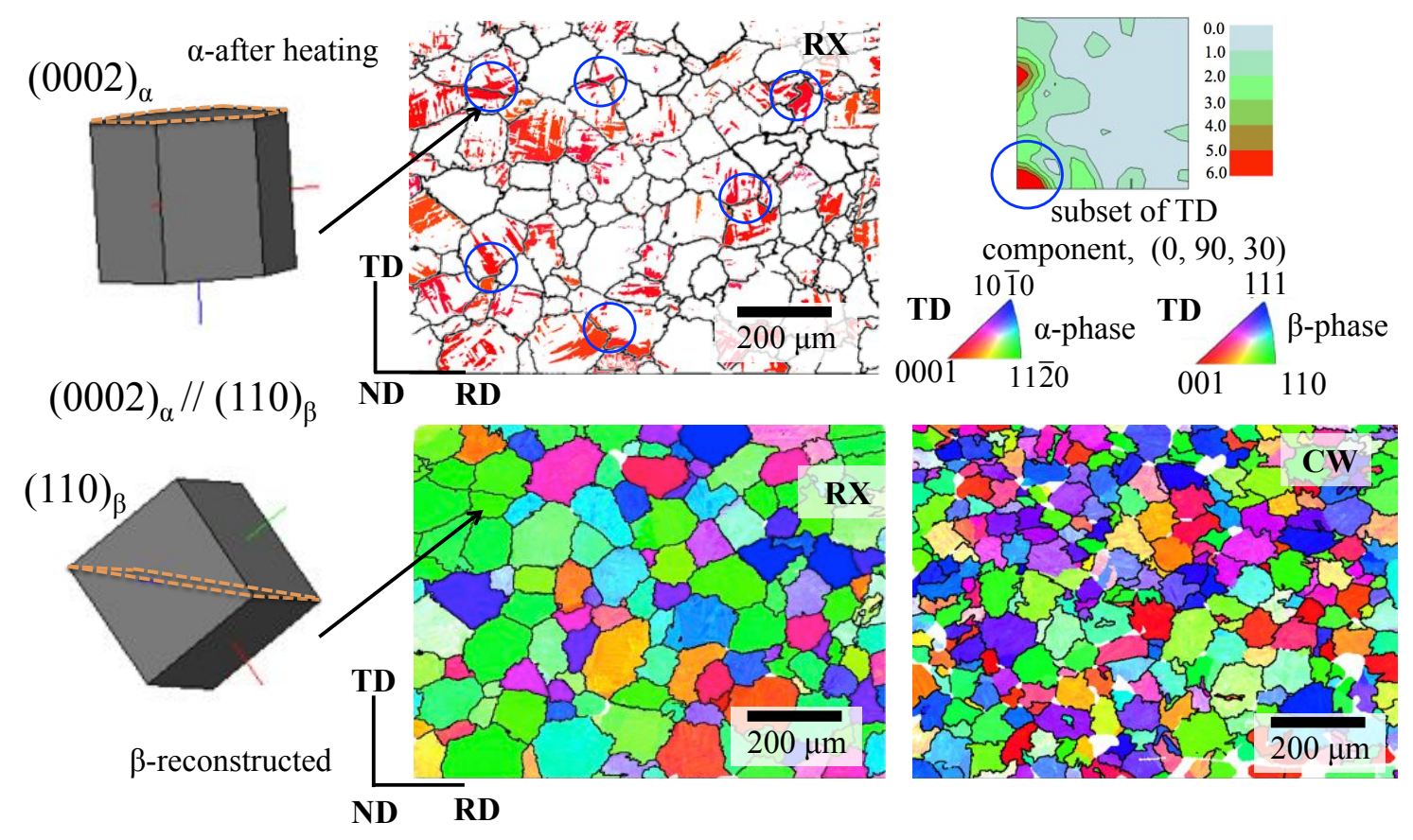

Fig. 9: The presence of $\alpha$-grains with similar orientations in transverse direction developed on both sides of the shared $110 \beta$-grain boundaries of RX Zircaloy-4 after the fast heating cycle, but not in the $\mathrm{CW}$ material. 
These results are in strong contradiction with those from experiments performed on pure titanium by Gey and Humbert [12]. In their experiment, CW titanium was heated at the same heating rate of $100^{\circ} \mathrm{Cs}^{-1}$, in a vacuum furnace, to $980^{\circ} \mathrm{C}$ before being held

for 30 seconds and cooling at $10^{\circ} \mathrm{Cs}^{-1}$. The resultant material has a very strong final $\alpha-$ texture and reconstructed $\beta$-texture [12], similar to those found here in the recrystallised material (Fig. 6a and Fig. 7a) and in CW Zircaloy-2 that is fully recrystallised on heating [9]. In the same study [12], a RX titanium heated using the same condition as the $\mathrm{CW}$ titanium has a weaker texture than the RX Zircaloy-4 studied here. This is opposite to the effect observed here on $\mathrm{Zr}$ alloys. This suggests that either the effect of $\mathrm{CW}$ on variant selection and texture is very different in $\mathrm{Ti}$ and $\mathrm{Zr}$ or that the $\mathrm{CW}$ titanium recrystallised on heating despite the same heating rate used here. One possible explanation is a difference in rolling reduction and hence stored energy. The strain in the $\mathrm{CW}$ Ti was almost twice than that in the $\mathrm{CW} \mathrm{Zr}$ alloy studied here, which provides a higher driving force for recrystallisation. Another possible explanation is that grain boundaries are pinned by small second phase particles (SPP's) in the zirconium alloy, which are stable up to high temperatures [42]. SPP's are known to slow the grain growth in the later stages of isothermal recrystallisation in $\mathrm{Zr}$ alloys, which explains the different grain sizes observed after recrystallisation between the CW Zircaloy-4 and CW Titanium $[43,44]$. Here SPP's would have slowed down recrystallisation during fast heating, allowing the deformed state to affect the phase transformation process. The texture produced by this fast recrystallisation process must be stronger than the starting Ti recrystallisation texture, giving rise to a strong transformed texture in the $\mathrm{CW}$ Ti.

\subsection{Summary of variant selection mechanism}

The differences in microstructure evolution that give rise to the different variant selection in CW and RX material are summarized in Fig. 10. In the RX samples, $\beta$ grains that nucleate on the straight grain boundaries of the fully recrystallised $\alpha$-grains can share the same Burgers' orientation relationship with their parent $\alpha$-grains. These $\beta$ grains are able to grow earlier, unimpeded across the $\alpha$-grains, eventually forming shared $\beta$-grain boundaries and strengthening the $\beta$-texture in the $\beta$-temperature region.

Upon cooling, $\alpha$-grains nucleate on these shared $110 \beta$ grain boundaries and grow with $0002_{\alpha} / / 110_{\beta}$ [39]. The early-nucleated $\alpha$-grains develop easily across their parent $\beta$ 
grains without any constraint and eventually become large $\alpha$-laths and the dominant components in the final $\alpha$-texture upon cooling.

In contrast, in the $\mathrm{CW}$ Zircaloy-4, fast heating rates result in the low-angle grain boundaries from the starting $\mathrm{CW}$ condition persist into phase transformation. This leads to two consequences on the transformed $\beta$-variant orientations. Firstly, since the $\alpha$ phase microstructure has jagged grain boundaries and the $\beta$-variants probably have a much wider range of orientations. Secondly, misorientation in the deformed grains prevents the early $\beta$-variants from growing, resulting in a greater contribution to the final texture of late nucleating $\beta$-variants, hence weakening the $\beta$-texture. As a result, the $\beta$-phase in $\mathrm{CW}$ samples has a weaker texture and rougher grain boundaries without shared 110 poles. On cooling, the absence of shared $110 \beta$-grain boundaries, leads to less variant selection, which also contributes to the random final texture in $\mathrm{CW}$ samples.

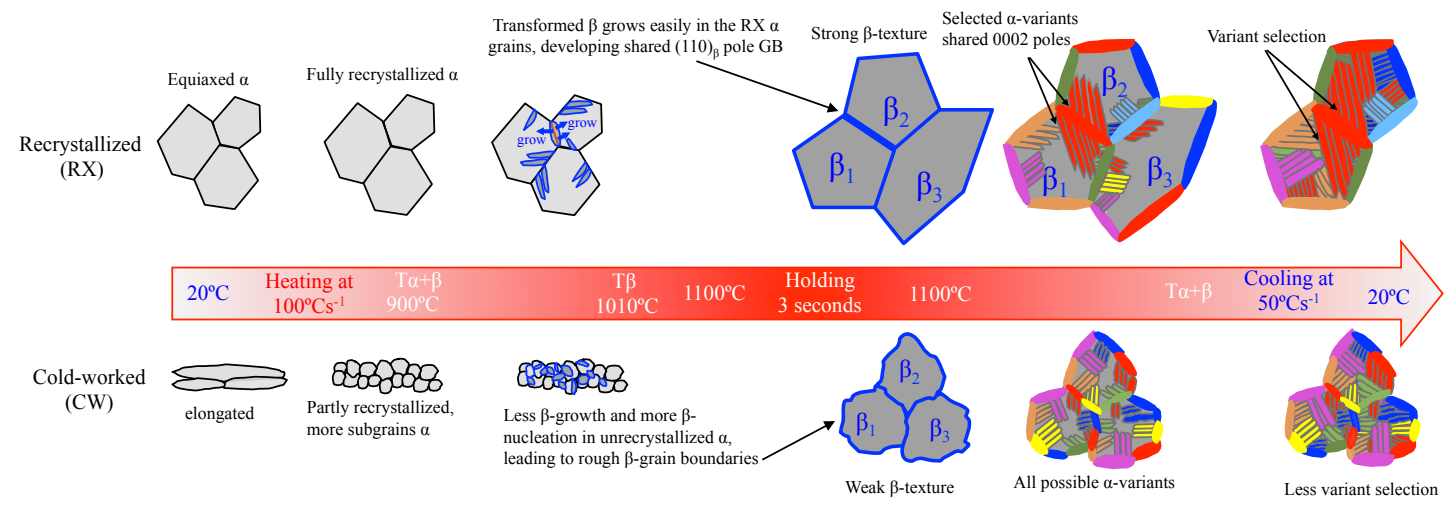

Fig. 10: Schematic representation of microstructure evolution during $\alpha \rightarrow \beta \rightarrow \alpha$ related to different starting microstructure of RX and CW under fast LOCA/RIA heating cycles.

\section{Conclusions}

The kinetics of phase transformation, microstructure and texture of Zircaloy-4 in two conditions, recrystallised and cold-worked, were studied by electrical resistance method and EBSD. The results show that cold work acts to delay the phase transformation and to slow down the transformation rate in the initial stages.

A fast $\beta$-cycle leads to weakened final $\alpha$-textures in both cold worked and recrystallised states. The texture after transformation is essentially random in the cold-worked material but somewhat stronger in the recrystallised material, with the development of a 
strong 0002 component in TD and tilted $\pm 20^{\circ}$ from ND towards TD. This difference can be explained by the difference in the texture and grain boundary network of the two conditions prior to the phase transformation, which exists because the high heating rate of $100^{\circ} \mathrm{Cs}^{-1}$ prevents the full recrystallisation of the cold worked material. Cold work leads to a weaker high temperature $\beta$-phase texture and less variant selection on cooling. This result is very different from previous work on Ti where $\mathrm{CW}$ and fast heating was shown to strengthen the texture and increase variant selection [12].

Zr fuel claddings are made of different zirconium alloys in different metallurgical states from cold-worked to fully recrystallised [45]. Therefore, understanding the effects of starting microstructure at high heating/cooling rates is of great practical importance. Furthermore, these finding are relevant to manufacturing processes with high heating rates like welding and additive layer manufacturing, and suggest that deformation could be an important mechanism of microstructure refinement that could be exploited.

\section{Acknowledgements}

The authors would like to thank EDF R\&D and Westinghouse Electric Co. for supporting the work and to Prof. Peter Bate for writing TEXTAN.

\section{References}

[1] H. Chung, Fuel Behavior under Loss-of-Coolant Accident Situations, Nucl. Eng. Technol. 37 (2005) 327-362.

[2] T. Forgeron, J. Brachet, F. Barcelo, A. Castaing, J. Hivroz, P. Mardon, et al., Experiment and modeling of advanced fuel rod cladding behavior under LOCA conditions: $\alpha-\beta$ phase transformation kinetics and EDGAR methodology, in: G.. Sabol, G.. Moan (Eds.), Zircon. Nucl. Ind. Twelfth Int. Symp. ASTM STP 1354, ASTM International, West Conshohocken, PA, 2000: pp. 256-278.

[3] E.W.C. R. Boyer, G. Welsch, Titanium alloys, ASM International, Materials Park, Ohio - USA, 1994.

[4] A.R. Massih, T. Andersson, P. Witt, M. Dahlbäck, M. Limbäck, Effect of quenching rate on the $\beta$-to- $\alpha$ phase transformation structure in zirconium alloy, $\mathrm{J}$. Nucl. Mater. 322 (2003) 138-151. doi:10.1016/S0022-3115(03)00323-4.

[5] W.G. Burgers, On the process of transition of the Cubic-Body-Centered modification into the Hexagonal-Closed-Packed modification of Zirconium, Physica. 1 (1934) 561-586. 
[6] N. Gey, M. Humbert, E. Gautier, J.L. Béchade, Study of the $\beta \rightarrow \alpha$ variant selection for a zircaloy- 4 rod heated to the $\beta$ transus in presence or not of an axial tensile stress, J. Nucl. Mater. 328 (2004) 137-145. doi:10.1016/j.jnucmat.2004.03.003.

[7] I. Lonardelli, N. Gey, H.-R. Wenk, M. Humbert, S.C. Vogel, L. Lutterotti, In situ observation of texture evolution during $\alpha \rightarrow \beta$ and $\beta \rightarrow \alpha$ phase transformations in titanium alloys investigated by neutron diffraction, Acta Mater. 55 (2007) 57185727. doi:10.1016/j.actamat.2007.06.017.

[8] M.R. Daymond, R.A. Holt, S. Cai, P. Mosbrucker, S.C. Vogel, Texture inheritance and variant selection through an hcp-bcc-hcp phase transformation, Acta Mater. 58 (2010) 4053-4066. doi:10.1016/j.actamat.2010.03.012.

[9] J. Romero, M. Preuss, J. Quinta da Fonseca, R.J. Comstock, M. Dahlbäck, L. Hallstadius, Texture Evolution of Zircaloy-2 During Beta-Quenching: Effect of Process Variables, J. ASTM Int. 7 (2010) 1-13. doi:10.1520/JAI103014.

[10] G.C. Obasi, S. Birosca, J. Quinta da Fonseca, M. Preuss, Effect of $\beta$ grain growth on variant selection and texture memory effect during $\alpha \rightarrow \beta \rightarrow \alpha$ phase transformation in Ti-6 Al-4 V, Acta Mater. 60 (2012) 1048-1058. doi:10.1016/j.actamat.2011.10.038.

[11] J. Romero, M. Preuss, J. Quinta da Fonseca, Texture memory and variant selection during phase transformation of a zirconium alloy, Acta Mater. 57 (2009) 5501-5511. doi:10.1016/j.actamat.2009.07.046.

[12] N. Gey, M. Humbert, Characterization of the variant selection occurring during the $\alpha \rightarrow \beta \rightarrow \alpha$ phase transformations of a cold rolled titanium sheet, Acta Mater. 50 (2002) 277-287. doi:10.1016/S1359-6454(01)00351-2.

[13] M. Canay, C.A. Dan, D. Arias, Phase transition temperature in the Zr-rich corner of $\mathrm{Zr} \pm \mathrm{Nb} \pm \mathrm{Sn} \pm \mathrm{Fe}$ alloys, J. Nucl. Mater. 280 (2000) 365-371.

[14] C. Toffolon, J.C. Brachet, C. Servant, L. Legras, D. Charquet, P. Barberis, et al., Experimental study and preliminary thermodynamic calculations of the pseudoternary Zr-Nb-Fe-(O, Sn) system, in: G.D. Moan, P. Rudling (Eds.), Zircon. Nucl. Ind. Thirteen. Int. Symp. ASTM STP 1423, ASTM International, West Conshohocken, PA, 2002.

[15] J. Brachet, L. Portier, T. Forgeron, Influence of hydrogen content on the $\alpha / \beta$ phase transformation temperatures and on the thermal-mechanical behavior of Zy-4, M4 (ZrSnFeV), and M5 (ZrNbO) alloys, in: G. Moan, P. Rudling (Eds.), Zircon. Nucl. Ind. Thirteen. Int. Symp. ASTM STP 1423, ASTM International, West Conshohocken, PA, 2002: pp. 673-701.

[16] O. Beneš, P. Van Uffelen, J. Van de Laar, C. Győri, R.J.M. Konings, Z. Hózer, Kinetic studies of the $\alpha-\beta$ phase transition in the $\mathrm{Zr} 1 \% \mathrm{Nb}$ cladding for nuclear reactors, J. Nucl. Mater. 414 (2011) 88-91. doi:10.1016/j.jnucmat.2010.12.034. 
[17] C.T. Nguyen, J. Romero, A. Ambard, M. Preuss, J. Quinta da Fonseca, Predicting the flow stress of Zircaloy-4 under in-reactor accident conditions, Zircon. Nucl. Ind. 18th Int. Symp. STP1597. (2017) 214-239.

[18] C. Angelier, S. Bein, J. Béchet, Building a Continuous Cooling Transformation Diagram of $\beta$-CEZ Alloy by Metallography and Electrical Resistivity Measurements, Metall. Mater. Trans. A. 28 (1997) 2467-2475.

[19] E. Tenckhoff, Review of deformation mechanisms, texture, and mechanical anisotropy in zirconium and zirconium base alloys, J. ASTM Int. 2 (2005) 1-77.

[20] G. Hörz, M. Hammel, H. Kanbach, Electrical resistivity of $\beta$-Zirconium-oxygen solid solutions as a function of oxygen concentration and temperature, J. Nucl. Mater. 55 (1975) 291-298.

[21] M. Corchia, F. Righini, Kinetic aspects of the phase transformations in Zircaloy2, J. Nucl. Mater. 97 (1981) 137-148.

[22] D. Arias, R. Guerra, Phase Transition Temperature in Zircaloy 2, J. Nucl. Mater. 144 (1987) 196-199.

[23] D. Kaddour, S. Frechinet, A.F. Gourgues, J.C. Brachet, L. Portier, A. Pineau, Experimental determination of creep properties of Zirconium alloys together with phase transformation, Scr. Mater. $51 \quad$ (2004) 515-519. doi:10.1016/j.scriptamat.2004.05.046.

[24] Z. Fan, A new approach to the electrical resistivity of two-phase composites, Acta Metall. Mater. 43 (1995) 43-49.

[25] M. Dahms, H. Bunge, The iterative series-expansion method for quantitative texture analysis. I. General outline, J. Appl. Crystallogr. 22 (1989) 439-447. doi:10.1107/S0021889889005261.

[26] S. Zaefferer, A critical review of orientation microscopy in SEM and TEM, Cryst. Res. Technol. 46 (2011) 607-628. doi:10.1002/crat.201100125.

[27] P.S. Davies, An investigation of microstructure and texture evolution in the nearalpha Titanium alloy Timetal 834, The University of Sheffield, 2009.

[28] M. Humbert, H. Moustahfid, F. Wagner, M.J. Philippe, Evaluation of the high temperature texture of the $\beta$ phase of a TA6V sample from the individual orientations of grains of the low temperature $\alpha$ phase, Scr. Metall. Mater. 30 (1994) 377-382.

[29] M. Humbert, F. Wagner, H. Moustahfid, C. Esling, Determination of the orientation of a parent $\beta$ grain from the orientations of the Inherited $\alpha$ plates in the phase transformation from Body-Centred Cubic to Hexagonal Close Packed, J. Appl. Crystallogr. 28 (1995) 571-576. doi:10.1107/S0021889895004067.

[30] N. Gey, M. Humbert, Specific analysis of EBSD data to study the texture inheritance due to the $\beta \rightarrow \alpha$ phase transformation, J. Mater. Sci. 38 (2003) 1289-1294. 
[31] H.J. Bunge, M. Humbert, P.I. Welch, Texture transformation, Textures Microstruct. 6 (1984) 81-96. doi:10.1016/0036-9748(83)90363-0.

[32] P. Bate, TEXTAN III - A program for the analysis of crystallographic texture using harmonic series expansion, Version 3., 1990.

[33] R. Holt, H.E. Sills, S. Sagat, Model for the kinetics of the alpha - beta phase transformation in Zircaloy-4, in: J.H. Gittus (Ed.), IAEA Spec. Meet. Fuel Elem. Perform. Comput. Model., The IAEA Austria, Blackpool, UK, 1980: pp. 17-20.

[34] J. Christian, The Theory of Transformations in Metals and Alloys, 3rd ed., Pergamon, Oxford, 2002.

[35] H. Bunge, Texture analysis in materials science, Butterworths, London, 1982.

[36] G.G.E. Seward, S. Celotto, D.J. Prior, J. Wheeler, R.C. Pond, In situ SEM-EBSD observations of the hcp to bcc phase transformation in commercially pure titanium, Acta Mater. 52 (2004) 821-832. doi:10.1016/j.actamat.2003.10.049.

[37] H.-R. Wenk, P. Van Houtte, Texture and anisotropy, Reports Prog. Phys. 67 (2004) 1367-1428. doi:10.1088/0034-4885/67/8/R02.

[38] M. Humbert, N. Gey, Elasticity-based model of the variant selection observed in the $\beta$ to $\alpha$ phase transformation of a Zircalloy-4 sample, Acta Mater. 51 (2003) 4783-4790. doi:10.1016/S1359-6454(03)00318-5.

[39] D. Bhattacharyya, G.. Viswanathan, R. Denkenberger, D. Furrer, H.L. Fraser, The role of crystallographic and geometrical relationships between $\alpha$ and $\beta$ phases in an $\alpha / \beta$ titanium alloy, Acta Mater. 51 (2003) 4679-4691. doi:10.1016/S1359-6454(03)00179-4.

[40] N. Stanford, P.S. Bate, Crystallographic variant selection in Ti-6Al-4V, Acta Mater. 52 (2004) 5215-5224. doi:10.1016/j.actamat.2004.07.034.

[41] C. Cayron, Importance of the $\alpha \rightarrow \beta$ transformation in the variant selection mechanisms of thermomechanically processed titanium alloys, Scr. Mater. 59 (2008) 570-573. doi:10.1016/j.scriptamat.2008.05.013.

[42] A. Miquet, D. Charquet, C.H. Allibert, Solide state phase equilibria of Zircaloy-4 in the temperature range $750-1050^{\circ} \mathrm{C}$, J. Nucl. Mater. 105 (1982) 132-141.

[43] F. Wagner, N. Bozzolo, O. Van Landuyt, T. Grosdidier, Evolution of recrystallisation texture and microstructure in low alloyed titanium sheets, Acta Mater. 50 (2002) 1245-1259. doi:10.1016/S1359-6454(01)00427-X.

[44] F. Gerspach, N. Bozzolo, F. Wagner, About texture stability during primary recrystallization of cold-rolled low alloyed zirconium, Scr. Mater. 60 (2009) 203-206. doi:10.1016/j.scriptamat.2008.09.031.

[45] K. Linga Murty, I. Charit, Texture development and anisotropic deformation of zircaloys, Prog. Nucl. Energy. 48 (2006) 325-359. doi:10.1016/j.pnucene.2005.09.011. 